\title{
О ВОЗМОЖНОСТИ ПРИМЕНЕНИЯ МИКРОМАГНИТНОИ СЪЕМКИ ПРИ ИЗУЧЕНИИ ТРЕЩИНОВАТОСТИ КОРЕННЫХ ПОРОД НА ЭСТОНСКОМ МЕСТОРОЖДЕНИИ ГОРЮЧИХ СЛАНЦЕВ
}

Микромагнитная съемка является новым методом изучения трещиноватости. Соответствующая методика разработана профессором Лейпцигского университета Р. Лаутербахом в 1953-1956 гг. (Buchheim u. Lauterbach, 1953; Lauterbach, 1953-1954, 1955-1956).

Сущность метода состоит в следующем. На небольшом участке (от $10 \times 10$ до $50 \times 50$ м) с незначительной мощностью наносов (до $5 \div 10$ м) проводятся высокоточные измерения вертикальной составляющей геомагнитного поля по густой сети пунктов наблюдений (с шагом $1 \div 5$ м). Выявленные при этом микроаномалии (по Р. Лаутербаху - «элементарные» магнитные аномалии) подлежат статистической обработке с построением роз направлений изодинам $\Delta Z$. Работами Р. Лаутербаха установлено, что в определенных условиях эти розы отражают трещиноватость горных пород на изученных участках.

Микромагнитные аномалии, связанные с трещиноватостью горных пород, обусловлены не только разностью магнитных свойств трещиноватых пород и заполняющего трещины материала, но и условиями намагничивания. Как доказал Р. Вендлер (Wendler, 1955-1956), характер причин связи мнкромагнитнык аномалий с трешинной тектоникой может рассматриваться по крайней мере с двух точек зрения: физической и химической. Первая из них опирается на экспериментально установленную зависимость между намагниченностью горных пород и упругими напряжениями.

В основе химического объяснения упомянутой связи лежат результаты исслецований, проведенных Р. Вендлером в ГДР. В ходе этих работ выяснилось, что микромагнитные аномалии над практически немагнитными породами (ракушечный известняк и песчаник) были обусловлены повышенной магнитной воспрнимчивостью материала, заполняющего трещины. Этот материал состоял в основном из гидроокисла железа (гётита), присутствовавшего либо в виде пленок на поверхности небольших гіо размерам зерен, либо в виде цементирующего материала. Таким образом, на характер микромагнитных аномалий в данном случае оказал влияние химический обмен в самих трещинах и вокруг них, согровождающийся процессами обогащения железистыми минералами.

Предлагаемая Р. Лаутербахом методика микромагнитной съемки дает положнтельные результаты только в определенных условиях. Таковыми являются условия залегания изучаемого объекта, магнитная анизотропность комплекса пород, отсутствие помех (влияние действующих шахт, устройств постоянного тока и т. д.), соблюденне определенной методики и техники полевых работ и определенных приемов обработки и интерпретации полученных данных.

С целью выяснения возможности применения микромагнитной съемки при изучении трещиноватости коренных пород в условиях Эстонского месторождения горючих сланцев Институт геологии АН ЭССР провел в полевом сезоне 1965 г. опытные работы в трех местах. В пределах этого месторождения, приуроченного к комплексу осадочных 
пород кукрузеского горизонта среднего ордовика, под четвертичным покровом небольшой мощности (обычно $3 \div 5$ м) выходят карбонатные породы разных горизонтов ордовика, характеризующиеся в общем моноклинальным залеганием с небольшим падением слоев на юг (под углом $5 \div 12$ мин).

Некоторые сведения о магнитных свойствах осадочных пород сланцевого бассейна Эстонии имеются в рукописном отчете, составленном И. Куллем (ИГ АН ЭССР) в 1961 г. По этим данным, магнитная восприимчивость $\varkappa 41$ образца известняков таллинского, кукрузеского, идавереского, йыхвиского и кейлаского горизонтов среднего ордовика равна $1 \div 14 \cdot 10^{-6} \mathrm{CGSM}\left(x_{\mathrm{cp}}=7 \cdot 10^{-6} \mathrm{CGSM}\right)$. Мергелистые известняки таллинского горизонта (6 образцов) имеют $\varkappa$ от 6 до $13 \cdot 10^{-6} \mathrm{CGSM}\left(x_{\mathrm{cp}}=\right.$ $=8 \cdot 10^{-6} \mathrm{CGSM}$ ), а горючие сланцы кукрузеского горизонта (27 образцов) - от 1 до $7 \cdot 10^{-6} \mathrm{CGSM}\left(\varkappa_{\mathrm{cp}}=5 \cdot 10^{-6} \mathrm{CGSM}\right)$. Глина из карстовых полостей в вышеуказанных карбонатных породах (4 образца) имеет $\varkappa$ от 14 до $19 \cdot 10^{-6}$ CGSM $\left(\varkappa_{\text {cp }}=16 \cdot 10^{-6}\right.$ CGSM). Значительно более магнитными оказались некоторые разновидности четвертичных отложений: морена на шахтном поле № 2 (1 образец, $x=105 \cdot 10^{-6}$ CGSM) и в Иыэляхтме (3 образца, $x$ от 300 до $390 \cdot 10^{-6}, \varkappa_{\mathrm{cp}}=350 \cdot 10^{-6}$ CGSM), ленточные глины из карьера Пылула (9 образцов, $x$ от 22 до $102 \cdot 10^{-6}$, $\left.x_{\mathrm{cp}}=57 \cdot 10^{-6} \mathrm{CGSM}\right)$.

Таким образом, в случае заполнения трещин четвертичными отложениями различие между магнитной восприимчивостью их и карбонатных коренных пород часто достаточно для возбуждения микромагнитных аномалий.

В ходе опытных работ в местных условиях пришлось решить ряд методических вопросов, в том числе такне, как оптимальные густота сети наблюдений и размер участка, требуемая точность съемки, выбор схемы наблюдений и приемов обработки результатов измерений и др.

Известно, что густота сети пунктов наблюдений зависит от размеров микроаномалий и глубины залегания возмущающих масс. Обычно расстояние между пунктами наблюдений выбирается равным половине предполагаемой глубины залегания кровли исследуемых пород (Федюк, 1958). Но при мощности наносов менее $1 \div 2$ это правило не применимо, так как практически трудно провести съемку с шагом меньше 1 м. При слишком разреженной сети наблюдений магнитное поле участка сглаживается и может вызвать расплывчатость розы направлений изодинам $\Delta Z$.

В случае больших площадей густая сеть пунктов наблюдений делает съемку экономически невыгодной. Вместе с тем следует помнить, что выбранные густота сети наблюдений и размер площади съемки должны обеспечить необходимое для статистической обработки количество информации и выявить характерные особенности строения изучаемого района.

В результате проведенных нами опытных работ установлено, что в условиях Северной Эстонии наиболее подходящими являются густота сети наблюдений $1 \times 1$ и $2 \times 2$ м и размер участков съемки в пределах от $10 \times 10$ до $20 \times 20$ м. Такой размер участков съемки достаточен для выявления особенностей распространения трещиноватости коренных пород, характерных для данного района. Это подтверждается и картиной фактического площадного распределения трещиноватости на обнажениях (рис. $1,6,4, a)$. Слишком ограниченная площадь участков может подчеркивать локальные изменения подчиненных направлений трещин, хто отражается и в розах трещиноватости (рис. 1,2$)$. 
o)
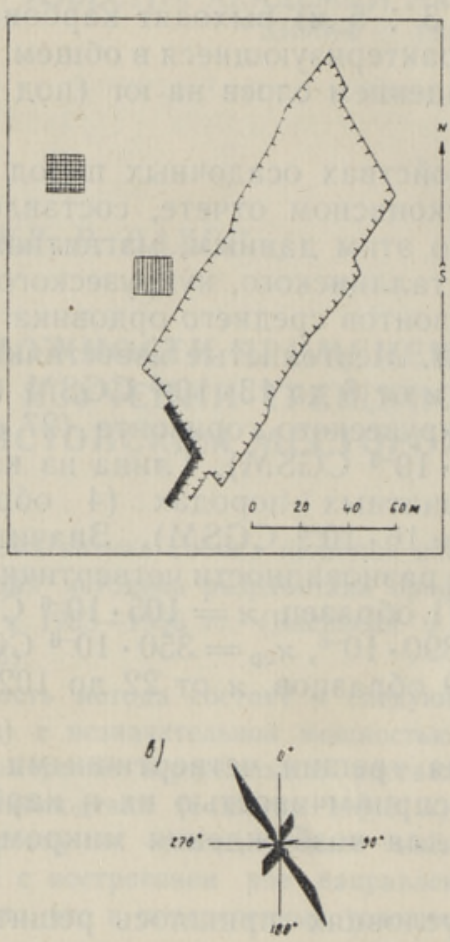

d)

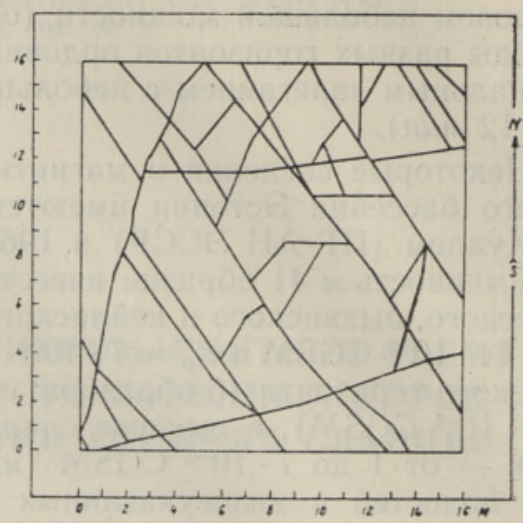

2)

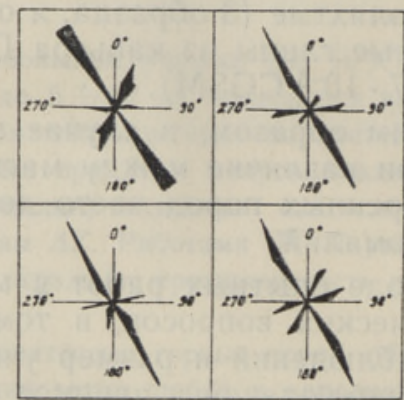

d)

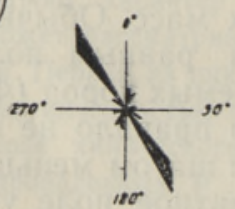

e)

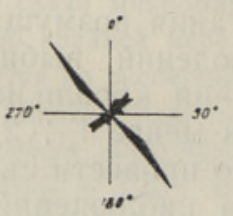

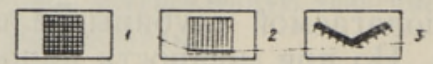

Рис. 1. Участок Кохтла-Ярве:

$a$ - схема расположения площадок наблюдений; 6 - площадное распространенне трещин на площадке $\mathrm{N}_{2} 2 ; \boldsymbol{B}-e-$ розы азимутов простирания трещнн: $\boldsymbol{\theta}-$ по площадке № 2, ᄅ - по квадрантам площадкн $\mathcal{N}_{2} 2, \partial-$ по стенкам карьера. $e$ - по канаве в 500 южнее карьера, 1 - площадка микромагнитной съемки: 2 - площадка наблюдения за трещиноватостью; 3 -. место наблюдення за трешиноватостью в карьере.

Рис. 2,б-е иллюстрирует изменения роз направлений изодинам $\Delta Z$ для участка Кохтла-Ярве (у карьера Сака) в зависимости от густоты сети и различных вариантов обработки наблюдений. На всех розах отмечаются одни и те же направления изолиний (иногда с отклонениями на $10^{\circ}$ ), меняется лишь относительная интенсивность лучей. Оптимальной в данном случае оказалась густота сети $2 \times 2$ м при однократных наблюдениях. На участке Йэляхтме сеть $2 \times 2$ м оказалась также более подходящей, чем сеть $4 \times 4$ м (рис. 3 ). На площадке у карьера Люганузе очень хорошие результаты получены при густоте сети 1 × 1 м (рис. 4): Мощность четвертичного покрова на указанных участках не превышала 0,5 м.

При оценке оптимальности густоты сети необходимо учитывать, как правильно отметила Т. Игнатьева (1958), что «при разной густоте сети, 
a)
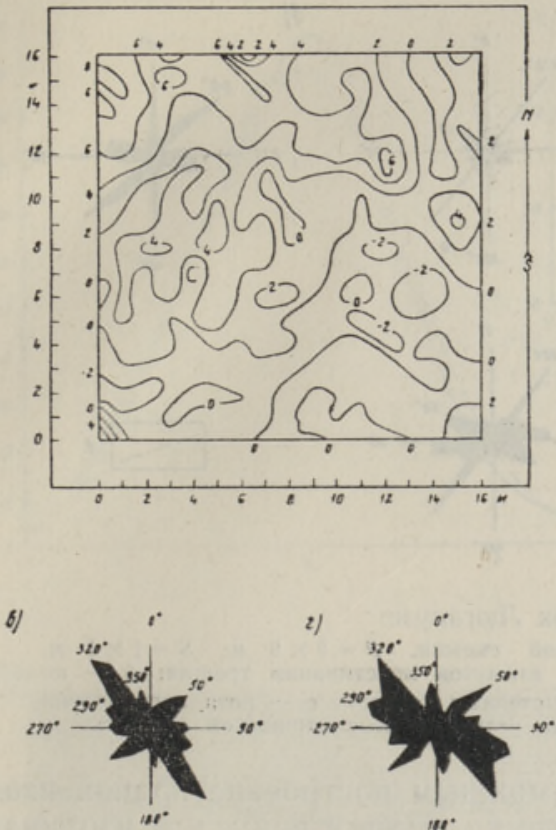

d)

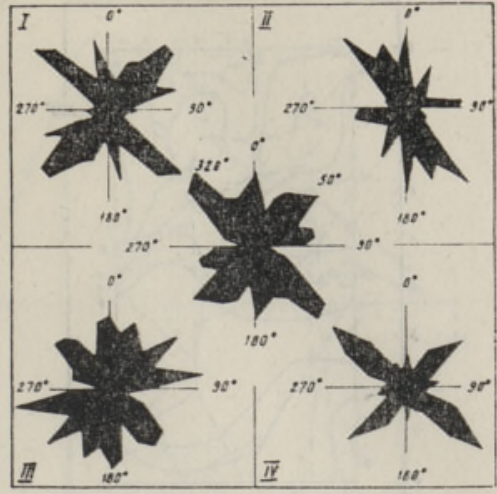

ग)

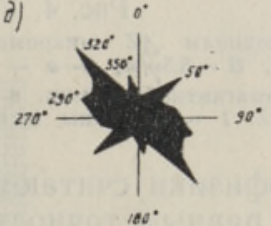

Рис, 2. Участок Кохтла-Ярве:

$a$ - план нзодинам $\Delta^{Z}$ микромагнитной съемки, $P=16 \times 16, \mu ; \quad S=1 \times 1, \mu, \quad D=2 \gamma$. $A=12 \gamma, \quad G=5,5 \gamma / \mu ; \quad 6-e-$ розы направлений изодннам $\Delta Z: 6-$ по квадрантам, $S=1 \times 1 \mathrm{M}$, двукратные наблюдения, в центре - сводная роза; $\theta-$ по первому измерению, $S=2 \times 2 \mu ; z-$ по второму измерению, $S=2 \times 2 \mu ; \partial-$ по двукратным наблюденням, $S=2 \times 2$ и: $e-$ по двукратным наблюдениям, $S=4 \times 4$ м. Здесь: $P$ - размер плошадки микромагннтной съемкн; $S=$ сеть наблюдений; $D$ - сечение изодинам; $A$ - максимальная амплитуда напряженности поля по $\Delta Z ; G-$ максимальный горизонтальның̆ градиент поля $\Delta Z$.

точности наблюдений и т. д. могут отмечаться различные детали строения пород участка и, вследствие этого, получаться несколько различные диаграммы направлений изолиний».

Измерение небольших по величине микромагнитных аномалий требует высокой точности съемки, зависящей от амплитуды напряженности магнитного поля в пределах участка.

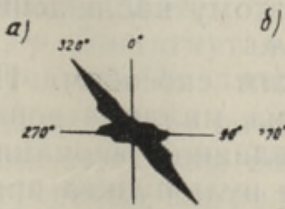

$100^{\circ}$

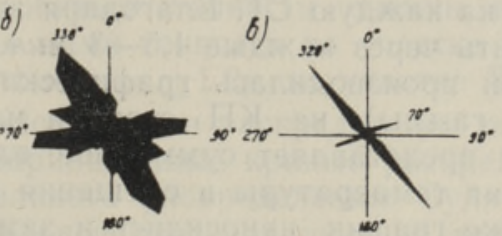

Рис. 3. Участок Йыляхтме: $a-6-$ розы направлений изодинам $\triangle Z: a-$ по сети $S=2 \times 2$ м; 6 - по сети $S=4 \times 4$ м; 8 в роза азимутов простирания трещин по обнаженню. $I$ - трещины. (Условные обознячения см. рис, 2)

В пределах опытных участков максимальная амплитуда напряженности магнитного поля по вертикальной составляющей $A=11 \div 16 \gamma$, максимальный горизонтальный градиент поля между двумя соседними точками наблюдений $G=5,5 \div 8,5 \gamma / \mu$. Интенсивность отдельных аномалий редко превышает $5 \div 6 \gamma$. Для оконтуривания столь слабых аномалий надо добиться точности съемки, позволяющей провести изодинамы $\Delta Z$ с сечением в $1 \div 3 \gamma$. Обычно планы изодинам $\Delta Z$ строят с ннтервалом изолинии, в 2-3 раза превышающим среднюю квадратическую погрешность измерений (Техническая инструкция..., 1963). В таком случае точность съемки должна быть в пределах от +0,5 до $\pm 1,5 \gamma$. 
a)

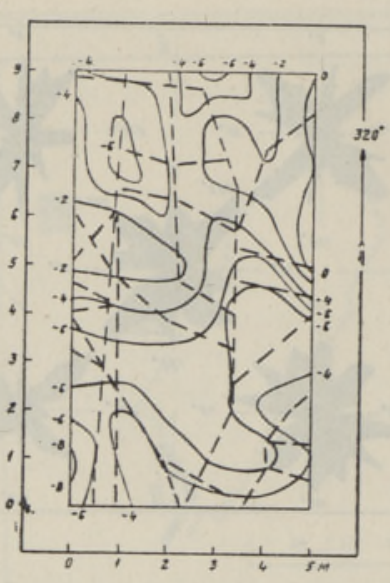

d)

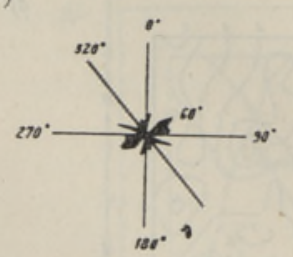

$\because$

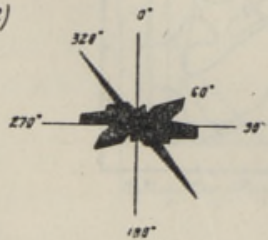

6)

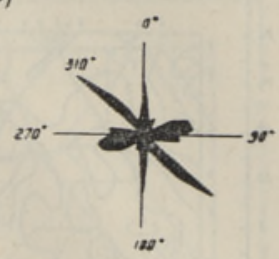

$120^{\circ}$

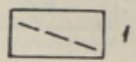

Рис. 4. Участок Люганузе:

$a$ - план изодинам $\Delta Z$ микромагнитной съемки, $P=5 \times 9$; $S=1 \times 1 M$, $D=2 \gamma, A=11 \gamma, G=8,5 \gamma / \mu ; \quad 6-8-$ розы азнмутов простирания трещин: $6-$ по площадке микромагнитной съемки, в - по стенкам карьера, 2 - роза направлений изодннам $\Delta^{Z} .1$ - трещины (остальные условные обозначения см. рис. 2 ).

Немецкие геофизики считают возможным построение планов изодинам с сечением, равным точности съемки, имея в виду, что изодинамы подлежат статистической обработке. По мнению В. Федюка (1958), этот вопрос является спорным. По нашему мнению, такая возможность все же заслуживает внимания, хотя требует проверки на практике.

Наблюдения проведены магнитометром M-14 (пронзводство завода «Геологоразведка»). Цена деления прибора $10 \gamma$, температурный коэффициент $2,4 \mathrm{\gamma} /{ }^{\circ} \mathrm{C}$. Чтобы добиться высокой точности съемки в условиях быстрого изменения вариации и для сравнения результатов одно- и двукратных наблюдений, испытывались схемы $\mathrm{K}-\mathrm{CT}_{1}-\mathrm{K} \Pi-\mathrm{CT}_{2} \ldots$ $\mathrm{K} \Pi-\mathrm{CT}_{\Pi}-\mathrm{K} \Pi$ и $\mathrm{K} \Pi-\mathrm{CT}_{1}-\mathrm{K} \Pi-\mathrm{CT}_{1}-\mathrm{K} \Pi-\mathrm{CT}_{2}-\mathrm{K} \Pi-\mathrm{CT}_{2} \ldots \mathrm{K} \Pi-$ $\mathrm{CT}_{\mathrm{n}}-\mathrm{K}$ - $\mathrm{CT}_{\mathrm{n}}-\mathrm{KП} \mathrm{(КП} \mathrm{-} \mathrm{контрольный} \mathrm{пункт,} \mathrm{СТ} \mathrm{-} \mathrm{съемочная}$ точка).

Для увеличения производительности измерений наблюдения осуществлялись с использованием двух штативов. Один из них оставался постоянно установленным на все время съемки планшета на КП. Второй штатив перемещался на каждую СТ. Благодаря этому наблюдения на КП удавалось проводить через каждые 1,5-3 мин.

Обработка наблюдений производилась графическим способом. По замерам (приведенным в гаммы) на КП строили на миллиметровке базисную линию, которая представляет суммарное влияние вариации магнитного поля, изменения температуры и смещения нуль-пункта прибора (рис. 5,8 ). На тот же график наносились и замеры на всех СТ. Затем производилось вычисление приращений вертикальной составляющей геомагнитного поля (с точностью $0,5 \gamma$ ) для каждой СТ относительно базисной линии, значение которой принималось за условный нуль.

Для оценки качества наблюдений производились контрольные измерения на всех СТ. Погрешность измерений (точность съемки) вычислялась по формуле средней квадратической погрешности отдельного измерения для случая парных наблюдений в $n$ точках

$$
\sigma= \pm \sqrt{\frac{\Sigma x_{i}-y_{i}}{2 n}}
$$




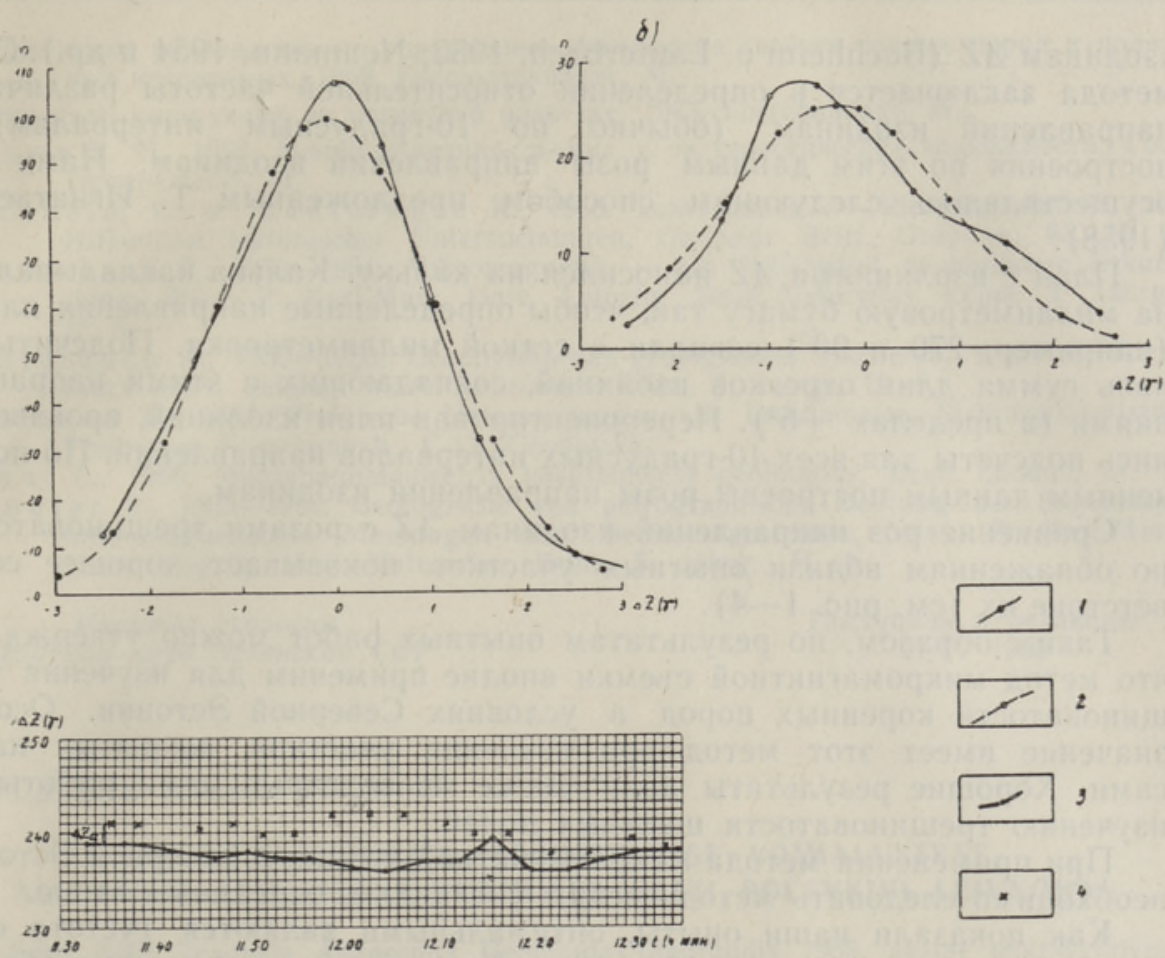

Рис. 5. Участок Кохтла-Ярве:

$a-6$ - вариационные кривые распределения разностей парных наблюдений: $a$ - по сети $S=1 \times 1$ м, $\varepsilon=1,1 \gamma, \lambda=0,53 ; 6$ - по сети $S=2 \times 2$, $, \varepsilon=1,0 \gamma$. $\lambda=1,2 ; в-$ графнк определення приращєннй $\Delta Z$. 1 - кривая фактического распределения; 2 -- теоретическая кривая нормального распределения; 3 - базисная линня; 4 - отсчеты на съемочных точках; $\varepsilon$ - среднеквадратическое отклонение отдельной разности парных наблюдений; $\lambda-$ критерий Колмогорова.

тде $x_{i}-y_{i}-$ разность значений $\Delta Z$ основного и повторного измерений (Методическое руководство. ., 1962).

По данным В. Федюка, вышеописанная схема однократных наблюдений позволяет добиться точности съемки в пределах от $\pm 0,7$ до $\pm 1,0 \gamma$. Достигнутая нами точность на участке Кохтла-Ярве $\sigma= \pm 0,8 \gamma$, на участке Иыэляхтме $\sigma= \pm 1,2 \gamma$, на участке Люганузе $\sigma= \pm 0,2 \gamma$.

Для оценки равномерности распределения разностей парных наблюдений построены вариационные кривые распределения и соответствующие кривые нормального распределения. Судя по критерию Колмогорова, экспериментальное распределение по всем трем опытным участкам хорошо соответствовало теоретическому. В качестве примера приводятся кривые по участку Кохтла-Ярве (рис. 5, $a, б)$.

Сравнение результатов одно- и двукратных наблюдений на участке Кохтла-Ярве показывает, что при хороших условиях измерения расхождение между розами направлений изодинам $\Delta Z$ весьма незначительно (см. рис. 2, в-д).

Результаты качественного анализа карт изодинам $\Delta Z$ всегда будут страдать элементом субъективизма. С целью объективной оценки планов изодинам микромагнитной съемки немецкими геофизиками разработана методика статистического анализа направлений (конфигурации) 
изодинам $\Delta Z$ (Buchheim u. Lauterbach, 1953; Neumann, 1954 и др.). Сугь метода заключается в определении относительной частоты различных направлений изодинам (обычно по 10-градусным интервалам) и построения по этим данным розы направлений изодинам. Нами это осуществлялось следующим способом, предложенным Т. Игнатьевой (1958).

План с изолиниями $\Delta Z$ наносился на кальку. Калька накладывалась на миллиметровую бумагу так, чтобы определенные направления плана (например, 270 и 90 ) совпали с сеткой миллиметровки. Подсчитывалась сумма длин отрезков изолиний, совпадающих с этими направлениями (в пределах $\pm 5^{\circ}$ ). Переориентировав план изолиний, производились подсчеты для всех 10-градусных интервалов направлений. По полученным данным построены розы направлений изодинам.

Сравнение роз направлений изодинам $\Delta Z$ с розами трещиноватости но обнажениям вблизи опытных участков показывает хорошее соответствие их (см. рис. $1-4)$.

Таким образом, по результатам опытных работ можно утверждать, что метод микромагнитной съемки вполне применим для изучения трещиноватости коренных пород в условиях Северной Эстонии. Особое значение имеет этот метод при изучении участков, закрытых наносами. Хорошие результаты дали также проведенные нами работы по изучению трещиноватости шахтных полей.

При применении метода микромагнитной съемки в Северной Эстонии необходимо следовать методическим указаниям, описанным выше.

Как показали наши опыты, оптимальными являются густота сети $2 \times 2 \mu$ и размер участка $16 \times 16 \mu$. Точность съемки должна обеспечить проведение изодинам с сечением в $1-3 \gamma$. Для оценки точности съемки и равномерности распределения погрешностей необходимо произвести контрольные измерения не менее чем в 25-30 точках. Кроме того, в точках с большими аномальными значениями и в случае резких изменений отсчетов на КП желательно произвести повторные измерения.

Наблюдения рекомендуется проводить по схеме $\mathrm{K}-\mathrm{CT}_{1}-\mathrm{K}$ П$\mathrm{CT}_{2} \ldots \mathrm{K}$ К-- $\mathrm{CT}_{n}-\mathrm{K}$ с использованием двух штативов. Если однократные наблюдения не обеспечивают требуемой точности, следует произвести двукратные наблюдения. Определение значений $\Delta Z$ на съемочных точках экономно графическим способом.

Для построения розы направлений изодинам $\Delta Z$ наиболее удобен способ суммирования длин отрезков изолиннй $\Delta Z$ по 10-градусным интервалам направлений.

Производительность микромагнитной съемки достаточно высока бригада из трех человек (оператор, вычислитель и рабочий) успевает за семичасовой рабочий день (при отсутствии дождя, сильного ветра и интенсивных магнитных вариаций) провести наблюдения в $100-$ 150 точках.

При применении микромагнитной съемки работу рекомендуется начинать вблизи обнажения, чтобы уточнить густоту сети наблюдений для района работ, проверить результаты и приобрести опыт.

Л И Т Е Р Т У P A

Игнатьева Т. С., 1958. Применение метода микромагнитной съемки к изучению трещиноватости пород, Обмен опытом. Вып. № 9, Бюро научно-техн. информации ВИТР МГ и ОН СССР, Л. 
Методическое руководство по определению физических свойств горных пород н полезных исконаемых, 1962. Госгеолтехиздат, $M$.

Техническая инструкция по магнитной разведке, 1963. Госгеолиздат, М.

Федюк В. И., 1958. Микромагнитная съемка и ее геологические возможности, Госгеолтехиздат, $M$.

Buchheim W. u. La uterbach R., 1953. Isoanomaien - Richtungsstatistik als Hilfsmittel tektonischer Untersuchungen, Gerlands Beitr. Geophys., 63, H. 2.

La uterbach R., 1953-1954. Mikromagnetik - ein Hilfsmittel geologischer Erkundung, Wiss. Z. Karl-Marx Univ. Leipzig. Math.-Naturwiss. Reihe, 3. Jahrg. H. 3 .

L a u t e r b a ch R., 1955-1956. Geophysikalisch-geologisches Kartieren, Wiss. Z. KarlMarx Univ. Leipzig. Math.-Naturwiss. Reihe, 5. Jahrg., H. 4.

N e u m a n n W., 1954. Praktische Untersuchungen zur Isoanomalen Richtungsstatistik, Freiberger Forschungsh., C-13, Geophysik.

P obul E., 1966. Mikromagnetomeetria kasutamisest geoloogias, Eesti Loodus, nr. 1. Wendler R., 1955-1956. Geologische und petrographische Deutung der Ergebnisse mikromagnetischer Messungen über Sedimentgesteinen, Wiss. Z. Karl-Marx Univ. Leipzig. Math.-Naturwiss. Reihe, 5. Jahrg., H. 4.

Институт геологии

Академии наук Эстонской ССР

\section{Поступила в редакцию} $27 /$ IV 1966

\section{E. POBUL, R. VAHER}

\section{MIKROMAGNETILISE MŌODISTAMISE VŌMALUSTEST ALUSPÖHJA LÖHELISUSE UURIMISEL EESTI PÓLEVKIVI LEIUKOHAS}

Eesti NSV Teaduste Akadeemia Geoloogia Instituudis 1965. aastal tehtud mikromagnetomeetrilised katsed näitasid, et kohtades, kus pinnakatte paksus ei ületa $5 \mathrm{~m}$, vōib aluspōhja lōhede suundi määrata mikromagnetilise meetodiga. Pōhja-Eestis osutus optimaalseks vaatlusvōrk, kus vaatluspunktid paiknevad tihedusega $2 \times 2 \mathrm{~m}$ ja môõolelapi suurus on $16 \times 16 \mathrm{~m}$. Mōōtmiste täpsus peab olema küllaldane $\Delta Z$ isodünaamide väljatõmbamiseks $1-3 \gamma$ tagant. Vajaliku täpsuse saavutamiseks on soovitatav teostada vaatlusi järgmise skeemi kohaselt: $\mathrm{KP}-\mathrm{VP}_{1}-\mathrm{KP}-\mathrm{VP}_{2} \ldots \mathrm{KP}-\mathrm{VP}_{n}-\mathrm{KP}$ (KP - kontrollpunkt, VP - vaatluspunkt). $\Delta Z$ isodünaamide plaani objektiivseks tōlgendamiseks summeeritakse $\Delta Z$ isodünaamide samasuunalised lôigud $10^{\circ}$ intervallide kaupa ja koostatakse nende alusel roosdiagramm. Viimane peegeidab aluspōhja lōhede levikusuundi antud kohas.

\section{E. POBUL, R. VAHER}

\section{ON POSSIBILITIES OF MICROMAGNETIC SURVEY IN THE STUDY OF THE JOINTING OF THE BEDROCK IN DEPOSITS OF ESTONIAN COMBUSTIBLE SHALE}

The micromagnetic tests carried out by the Institute of Geology of the Academy of Sciences of the Estonian SSR in 1965 showed that directions of joints in the bedrock can be defined by the micromagnetic method in places where the thickness of the overburden does not exceed $5 \mathrm{~m}$. In North Estonia, the network of observations proved to be optimal where the points of observation are located at a distance of $2 \times 2 \mathrm{~m}$, and the size of the measuring place is $16 \times 16 \mathrm{~m}$. The accuracy of measurement must be sufficient for drawing $\Delta Z$ isodynamic lines at each $1-3 \%$. For obtaining sufficient accuracy, it is advisable to carry out observations according to the following scheme: RP (reference point) - MP (measuring point) $-\mathrm{RP}-\mathrm{MP}_{2} \ldots \mathrm{RP}-\mathrm{MP}_{n}-\mathrm{RP}$ For an objective interpretation of the plan of $\Delta Z$ isodynamic lines, the sections of $\Delta Z$ isodynamic lines of the same direction are added up at intervals of $10^{\circ}$, and on this basis a rose diagram is compiled. The latter reflects the direction of the distribution of joints in the bedrock in a given site. 